\title{
Composto exaurido do cogumelo Agaricus blazei na dieta de frangos de corte
}

\section{Alexandre Magno Batista Machadoํㅜㄹ Eustáquio Souza Dias² ${ }^{2}$ Éder Clementino dos Santos ${ }^{3}$, Rilke Tadeu Fonseca de Freitas ${ }^{4}$}

\author{
${ }^{1}$ Mestre em Microbiologia Agrícola pela UFLA. Professor da EAFI-MG, Inconfidentes \\ 2 Departamento de Biologia da UFLA, Lavras. \\ ${ }^{3}$ Departamento de Zootecnia da EAFI-MG, Inconfidentes. \\ ${ }^{4}$ Departamento de Zootecnia da UFLA, Lavras.
}

RESUMO - Avaliou-se o efeito da substituição de um antibiótico por diferentes níveis do composto exaurido do cogumelo (CEC) Agaricus blazei sobre o desempenho de frangos de corte de 1 a 42 dias de idade. Foram avaliadas sete dietas, seis com adição de CEC $(0,0 ; 0,2 ; 0,4 ; 0,6 ; 0,8$ e 1,0\%) e uma com antibiótico (avilamicina 10 ppm). Foram utilizados 588 pintos de 1 dia de idade, distribuídos em um delineamento inteiramente casualizado, com seis repetições por dieta (três por sexo) e 14 aves por unidade experimental. As aves que não receberam qualquer aditivo na dieta apresentaram os piores resultados de desempenho. Níveis de CEC superiores a $0,4 \%$ ocasionaram redução gradual no desempenho. O nível de 0,2\% de CEC proporcionou o maior ganho de peso e o de $0,21 \%$, a melhor conversão alimentar e o maior consumo de ração. À exceção do rendimento de peito e do rendimento de gordura abdominal, os aditivos não influenciaram os rendimentos de carcaça e dos cortes. O composto exaurido do cogumelo Agaricus blazei pode ser utilizado como aditivo alternativo ao antibiótico no nível de $0,2 \%$ da dieta, pois não prejudicou o desempenho produtivo e o rendimento de carcaça das aves.

Palavras-chave: aditivos, antibióticos, aves de corte, desempenho, fungos medicinais, nutrição

\section{Spent mushroom substrate of Agaricus blazei in broiler chicks diet}

\begin{abstract}
The effect of the substitution of an antibiotic by different levels of spent mushroom substrate (SMS) of Agaricus blazei on the performance of broiler chicks from 1 to 42 days old was evaluated. Seven diets were evaluated, six with SMS addiction $(0.0,0.2,0.4,0.6,0.8$, and $1.0 \%)$ and one with antibiotic (avilamycin $10 \mathrm{ppm}$ ). A total of 588 one day old chicks was allotted to a complete randomized design, with six replications per diet (three per sex) and 14 birds per experimental unit. The birds fed diet with any additive showed the worst performance results. Levels of SMS above $0.4 \%$ caused gradual reduction in the performance. The level of $0.2 \%$ of SMS provided the highest value of weight gain and of $0.21 \%$ promoted the best feed conversion and the highest value of feed intake. With exception of chest and abdominal fat yield, no additive effect on carcass and cuts yield was observed. The spent mushroom substrate of Agaricus blazei can be used as additive alternative to the antibiotic at the level of $0.2 \%$ of the diet; therefore it did not harm the productive performance and carcass yields of the birds.
\end{abstract}

Key Words: addictives, antibiotics, broilers, medicinal fungi, nutrition, performance

\section{Introdução}

O uso de antibióticos como aditivos promotores de crescimento na avicultura tem sido bastante questionado atualmente. Há uma forte campanha para banir o uso dos antimicrobianos na produção animal, como medida cautelar, embasada na alegação de que as moléculas de alguns desses aditivos apresentam semelhanças com a de antibióticos utilizados na terapêutica humana, o que poderia, por meio do uso indiscriminado e contínuo, induzir, por pressão seletiva, a emergência de bactérias patogênicas multirresistentes a essas drogas (Edqvist \& Pedersen, 2002).
Essa afirmativa, entretanto, ainda não foi satisfatoriamente comprovada em estudos científicos.

A preocupação do consumidor com a segurança alimentar é outro fator que tem gerado um crescente posicionamento contrário ao uso de antimicrobianos na pecuária, bem como ao uso de quaisquer outros aditivos químicos.

É necessário salientar que, por trás de alegações sobre a segurança dos antibióticos e da necessidade de satisfazer às exigências dos consumidores, podem esconder-se interesses diversos, geralmente econômicos, que servem como pretexto para a adoção de medidas protecionistas em detrimento de países exportadores visando preservar mercados 
de países menos competitivos ou com produção interna insuficiente, como os da União Européia (Palermo-Neto, 2003). Nesse cenário, a iminente proibição do uso de antibióticos força países exportadores, inclusive o Brasil, a adequarem sua produção avícola às exigências do mercado internacional e a intensificarem a busca por alternativas ao uso dessas drogas como aditivos.

Uma linha de pesquisa que tem ganhado espaço neste contexto é a utilização de substâncias bioativas, extraídas de determinadas espécies de fungos basidiomicetos, referidos popularmente como cogumelos medicinais (Wong et al., 1994). Entre estas substâncias, destacam-se os polissacarídeos pertencentes ao grupo $\beta$-glucanas, conhecidos por sua atuação como estimulantes da atividade imunológica do hospedeiro (Mizuno et al., 1998). Independentemente da forma de utilização dessas substâncias - purificadas ou não, oriundas dos basidiomas ou do micélio vegetativo ou mesmo do caldo de cultivo do micélio em meio líquido (exopolissacarídeos) - na tentativa de substituir os antimicrobianos na avicultura, os resultados obtidos são cada vez mais promissores.

O cogumelo Agaricus blazei, recentemente testado com êxito em linhagens comerciais de frangos de corte, tem se apresentado como uma alternativa potencial aos antibióticos (Fuini, 2001; Santos et al., 2003). O fungo, popularmente conhecido como cogumelo-de-deus, cogumelo-piedade, cogumelo-do-sol, entre outros nomes, tem atraído bastante atenção do meio científico por apresentar compostos biologicamente ativos de interesse terapêutico (Dias et al., 2002). Há vários estudos sobre os efeitos antitumorais dos polissacarídeos extraídos de A. blazei (Fujimyia et al., 1998; Fujimyia et al., 1999; Reshetnikov et al., 2001; Mizuno, 2002). Essas propriedades estão relacionadas ao estímulo da resposta imunológica dessas macromoléculas (pertencentes ao grupo $\beta$-glucanas) no indivíduo, o que envolve ativação de células imunocompetentes e/ou seus mediadores químicos (Daba \& Ezeronye, 2003).

Estudos comprovaram que os polissacarídeos bioativos de A. blazei não estão presentes apenas no corpo de frutificação, mas por todo o micélio vegetativo que compõe a massa micelial e permeia o substrato de cultivo ( Ito et al., 1997; Kumar et al., 1999; Mizuno et al., 1999). Esse substrato, após o ciclo produtivo, é conhecido como composto exaurido de cogumelo e, apesar das pesquisas sobre seus meios de reutilização, na prática, normalmente o material é descartado ou usado como adubo orgânico (Rinker, 2002). O objetivo nesse trabalho foi avaliar o efeito da adição de composto exaurido de A. blazei (CEC) em substituição aos antibióticos na dieta de frangos de corte.

\section{Material e Métodos}

O experimento foi realizado no período de agosto a outubro de 2003. Foram utilizados 588 pintos de corte, linhagem Avian, sexados, com 1 dia de idade, vacinados contra doença de marek e bouba aviária. As aves foram alojadas em galpão de alvenaria coberto com telhas de cimento amianto, onde foram distribuídas em boxes de $4,7 \mathrm{~m}^{2}(2,55 \times 1,85)$ forrados com cama de palha de café reutilizada, portanto, com elevado nível de desafio sanitário. O delineamento experimental foi inteiramente casualisado, com os tratamentos em arranjo fatorial $7 \times 2$ (sete dietas experimentais e dois sexos - macho e fêmea). Das sete dietas experimentais, seis foram formuladas com diferentes níveis de composto exaurido de cogumelo $(0,0 ; 0,2 ; 0,4 ; 0,6 ; 0,8 \mathrm{e}$ $1,0 \%$ da dieta) e apenas uma com antibiótico (avilamicina 10 ppm). Cada dieta foi fornecida a seis parcelas (três com aves machos e três com aves fêmeas), com 14 aves por parcela. As dietas foram formuladas à base de milho, farelo de soja e óleo de soja e suplementadas com vitaminas e minerais de acordo com as recomendações de Rostagno et al. (2000) (Tabela 1). Tanto as dietas como a água foram fornecidas à vontade. Aos 42 dias de idade, efetuou-se a pesagem das aves e das sobras de alimento para avaliação do desempenho zootécnico. Os parâmetros de desempenho analisados foram o consumo de racao (CR), o ganho de peso (GP) e a conversão alimentar (CA). Ao término do período experimental, foram pesadas e abatidas duas aves por parcela após jejum de 6 horas. As aves foram evisceradas e as carcaças pesadas com cabeça, pescoço, pés e gordura abdominal. Foram avaliados os rendimentos do peso vazio ao abate (PV) das carcaças evisceradas com cabeça e pés (RC) e os rendimentos de peito (RP), asa (RASA), coxa (RCX), sobrecoxa (RSCX) e gordura abdominal (RGAB) e, ainda, o comprimento do intestino (CINT). O rendimento de carcaça foi calculado com base no peso vivo ao abate e os rendimentos das partes nobres e de gordura abdominal em relação ao peso da carcaça eviscerada.

O composto exaurido do cogumelo A. blazei (CEC) foi desidratado em estufa a $110^{\circ} \mathrm{C}$ por 12 horas e posteriormente foi triturado em moinho com malha de $1 \mathrm{~mm}$, de modo a obter pó fino e possibilitar fácil homogeneização na dieta.

As análises de variâncias dos dados de desempenho e de rendimento de carcaça foram realizadas de acordo com o seguinte modelo estatístico:

$$
\mathrm{Y}_{\mathrm{ijk}}=\mu+\mathrm{D}_{\mathrm{i}}+\mathrm{S}_{\mathrm{j}}+\mathrm{DS}_{\mathrm{ij}}+\mathrm{e}_{\mathrm{ijk}}
$$

em que $Y_{\mathrm{ijk}}=$ observação $\mathrm{k}$ da dieta i no sexo j; $\mu$ = média geral do experimento; $\mathrm{D}_{\mathrm{i}}=$ efeito da dieta $\mathrm{i}(\mathrm{i}=1,2, \ldots, 7)$; $S_{j}=$ efeito do $\operatorname{sexoj}\left(j=1\right.$ e 2); $D_{i j}=$ efeito da interação dieta $\mathrm{i} \times \operatorname{sexo} \mathrm{j}$; e $\mathrm{e}_{\mathrm{ijk}}=$ erro associado a cada observação, que, 
Tabela 1 - Composição e valores nutricionais da dieta basal Table 1 - Composition and nutritional values of basal diet

\begin{tabular}{lcc}
\hline $\begin{array}{l}\text { Ingrediente } \\
\text { Ingredient }\end{array}$ & $\begin{array}{c}\text { Fase inicial }^{1} \\
\text { Initial phase }^{2}\end{array}$ & $\begin{array}{c}\text { Fase final } \\
\text { Final phase }\end{array}$ \\
\hline Milho (Corn) & 57,103 & 62,774 \\
Farelo de soja (Soybean meal) & 36,457 & 30,244 \\
Óleo de soja (Soybean oil) & 2,831 & 3,396 \\
Fosfato bicálcico (Dicalcium phosphate) & 1,568 & 1,428 \\
Calcário calcítico (Limestone) & 1,205 & 1,137 \\
Cloreto de colina (60\%) & 0,050 & 0,050 \\
Sal comum (Salt) & 0,422 & 0,385 \\
DL-metionina (99\%) (DL-methionine) & 0,158 & 0,180 \\
L-lisina (78\%) (L-lysine) & 0,005 & 0,190 \\
Suplemento mineral (Mineral suppl.) & 0,050 & 0,100 \\
Suplemento vitamínico (Vitamin suppl.) & 0,050 & 0,100 \\
Caulin (Kaolin) & 0,101 & 0,016 \\
\hline
\end{tabular}

Nível nutricional

Nutritional level

\begin{tabular}{lcc}
\hline MS (\%) (DM) & 88,68 & 88,45 \\
EM (kcal/kg) (ME) & 3.000 & 3.100 \\
PB (\%) (CP) & 21,30 & 18,90 \\
Met + cis (\%) (Meth + cys) & 0,820 & 0,800 \\
Lisina (\%) (Lysine) & 1,180 & 1,150 \\
Ca (\%) & 1,024 & 0,942 \\
P disponível (\%) (Available P) & 0,440 & 0,400 \\
\hline
\end{tabular}

${ }^{1} \mathrm{O}$ antibiótico foi suplementado nas dietas em substituição ao material inerte (caulin).

${ }^{1}$ The antibiotic was supplemeed in diets in substitution to inert material (kaolin).

por pressuposição, é normalmente independentemente distribuído com média zero e variância $\sigma^{2}$.

Para a determinação do melhor nível de CEC nas dietas das aves, foram realizadas análises de regressão linear, optando-se pelo modelo de melhor ajuste, utilizando-se o programa estatístico SAEG - Sistema de Análises Estatísticas e Genéticas (UFV, 1997). As médias obtidas para cada nível de CEC foram comparadas às da dieta com antibiótico, por meio do teste Dunnet a $5 \%$ de probabilidade, enquanto as médias obtidas em cada um dos sexos foram comparadas pelo teste $\mathrm{F}$ a $5 \%$ de probabilidade.

\section{Resultados e Discussão}

Os resultados de desempenho das aves aos 42 dias de idade encontram-se na Tabela 2.

Não houve interação dieta $\times$ sexo, mas observou-se efeito $(\mathrm{P}<0,5)$ da dieta e do sexo sobre o desempenho. $\mathrm{O}$ desempenho das aves alimentadas com a dieta sem aditivos foi pior em que o daquelas alimentadas com a dieta contendo antibiótico, tanto em consumo como em ganho de peso, o que sugere a existência de desafio sanitário. Verificou-se também que a conversão alimentar nessas aves foi maior em relação à daquelas alimentadas com a dieta contendo antibiótico, evidenciando que a ausência de antibiótico ou de CEC pode ter afetado negativamente a eficiência
Tabela 2 - Desempenho de frangos de corte no período de 1 a 42 dias de idade alimentados com dietas com antibióticos ou com diferentes níveis do composto exaurido do cogumelo (CEC)

Table 2 - Broiler chickens performance from 1 to 42 days old fed diets with antibiotic or different levels of spent mushroom substrate (SMS)

\begin{tabular}{lccc}
\hline $\begin{array}{l}\text { Nível de CEC (\%) } \\
\text { SMS level }\end{array}$ & $\begin{array}{c}\text { Consumo (g) } \\
\text { Intake }\end{array}$ & $\begin{array}{c}\text { Ganho de } \\
\text { peso (g) } \\
\text { Weight gain }\end{array}$ & $\begin{array}{c}\text { Conversão } \\
\text { alimentar } \\
\text { Feed:gain ratio }\end{array}$ \\
\hline 0,0 & $3.750,7^{*}$ & $1.929,7^{*}$ & $1,93^{*}$ \\
0,2 & $3.970,0$ & $2.248,3$ & 1,80 \\
0,4 & $4.002,0$ & $2.222,7$ & 1,82 \\
0,6 & $4.010,8$ & $2.139,2$ & 1,87 \\
0,8 & $4.014,8$ & $2.132,8$ & 1,88 \\
1,0 & $4.016,3$ & $2.042,5^{*}$ & $1,97^{*}$ \\
Antibiótico & $4.078,8$ & $2.242,8$ & 1,83 \\
Antibiotic & & & $1,83 \mathrm{~b}$ \\
Macho & $4.069,2 \mathrm{a}$ & $2.233,5 \mathrm{a}$ & $1,90 \mathrm{a}$ \\
$\begin{array}{l}\text { Male } \\
\text { Fêmea }\end{array}$ & $3.886,0 \mathrm{~b}$ & $2.034,7 \mathrm{~b}$ & 1,87 \\
$\begin{array}{l}\text { Female } \\
\text { Média geral }\end{array}$ & $3.977,6$ & $2.134,1$ & \\
Overall mean & & & 4,158 \\
CV (\%) & 4,085 & 4,335 & \\
\hline
\end{tabular}

* Diferem do tratamento controle (antibiótico) pelo teste Dunnet $(P<0,05)$. Médias com letras minúsculas distintas na mesma coluna diferem $(P<0,05)$ pelo teste $\mathrm{F}$.

* Differs $(P<0.05)$ from the control treatment (antibiotic) by Dunnet test.

Means, within a column, with different small letters differ $(P<0.05)$ by test $F$.

alimentar das aves. O desempenho das aves alimentadas com as dietas contendo de 0,2 até $0,8 \%$ de CEC foi semelhante $(\mathrm{P}<0,5)$ ao daquelas que consumiram a dieta contendo apenas antibiótico, o que não foi observado nas aves alimentadas com a dieta contendo 1,0\% de CEC, que apresentaram menor ganho de peso e pior conversão alimentar, provavelmente em decorrência dos efeitos antinutricionais da maior quantidade de fibras alimentares presentes na dieta das aves que receberam o maior nível de CEC. De acordo com Montagne et al. (2003), altos teores de fibra alimentar elevam a velocidade do fluxo da digesta pelo trato intestinal, reduzindo, conseqüentemente, a assimilação de nutrientes pelo organismo. Nas análises de regressão do consumo, do ganho de peso e da conversão alimentar nos diferentes níveis de CEC, nenhum dos modelos avaliados (linear e quadrático) foi significativo ou se ajustou adequadamente aos dados. Entretanto, na Figura 1, verificam-se aumentos lineares acentuados no consumo e no ganho de peso das aves alimentadas com dietas com $0,2 \%$ de CEC e que, a partir desse nível, o desempenho das aves piorou. A dieta com $0,21 \%$ de CEC proporcionou o melhor resultado de conversão alimentar (Figura 1), o que comprova melhor eficiência alimentar e melhor desempenho zootécnico das aves alimentadas com essa dieta.

Os resultados obtidos neste trabalho estão de acordo com os encontrados por outros autores em estudos seme- 
lhantes. Guo (2003) testou diferentes níveis de extratos do cogumelo Lentinula edodes $(0,05 ; 0,1 ; 0,2 ; 0,3$ e $0,4 \%)$, conhecido por também apresentar polissacarídeos imunoestimulantes, em substituição ao antibiótico na dieta de frangos de corte e observou que o maior ganho de peso e a melhor conversão alimentar foram obtidos com o nível de $0,2 \%$ de extrato de cogumelo. Fuini (2001) avaliou o efeito dos níveis $(0,00 ; 0,25 ; 0,50 ; 0,75$ e 1,00\%) de corpos de frutificação de Agaricus blazei, desidratados e moídos, em substituição a antimicrobiano na dieta de aves de corte e verificaram que o nível de $0,25 \%$ possibilitou o maior ganho de peso e a melhor conversão alimentar.

Alguns fatores podem explicar o efeito positivo de CEC sobre o desempenho das aves; a fina granulometria do CEC, obtida após a moagem, possibilitou uma mistura bastante homogênea com a dieta e garantiu bom aproveitamento do material pelas aves.

As características do CEC podem ter influenciado o equilíbrio do ecossistema intestinal das aves e favorecido a microbiota, servindo-lhe de substrato. É possível que essa microbiota seja capaz de realizar a fermentação dos componentes fibrosos do CEC, provocando redução do $\mathrm{pH}$ luminal pela produção de ácidos orgânicos resultantes de seu metabolismo, o que inibe a ação de bactérias patogênicas na mucosa intestinal (Silva \& Nörnberg, 2003). Outra forma de atuação do CEC no balanço da microbiota intestinal seria pela adsorção das bactérias patogênicas às suas partículas, promovendo maior translocação desses patógenos e impedindo que colonizem as células do epitélio intestinal.

Sabe-se que o micélio vegetativo das espécies de fungos basidiomicetos consideradas medicinais também apresenta substâncias bioativas, constituídas principalmente por polissacarídeos do grupo $\beta$-glucanas. Esse fato também foi comprovado em A. blazei (Ito et al., 1997; Reshetnikov et al., 2001; Kumar et al., 1999). Essas substâncias, presentes na massa micelial que compõe o CEC, após serem absorvidas pela mucosa do trato intestinal, podem ter atuado como agentes estimulantes da resposta imunológica das aves, tornando-as menos susceptíveis à ação de patógenos adquiridos via alimentação.

Em termos de potencial genético das aves, Huyghebaert (2003) informou que a expressão fenotípica responsável pelos altos índices de produtividade da avicultura atual é fortemente vinculada à atividade imunológica, daí a necessidade de se ter um sistema imune bem desenvolvido e uma resposta imunológica eficiente. Os fatores bioativos presentes no CEC de A. blazei podem ter estimulado a resposta imune e reduzido o estresse resultante do impacto

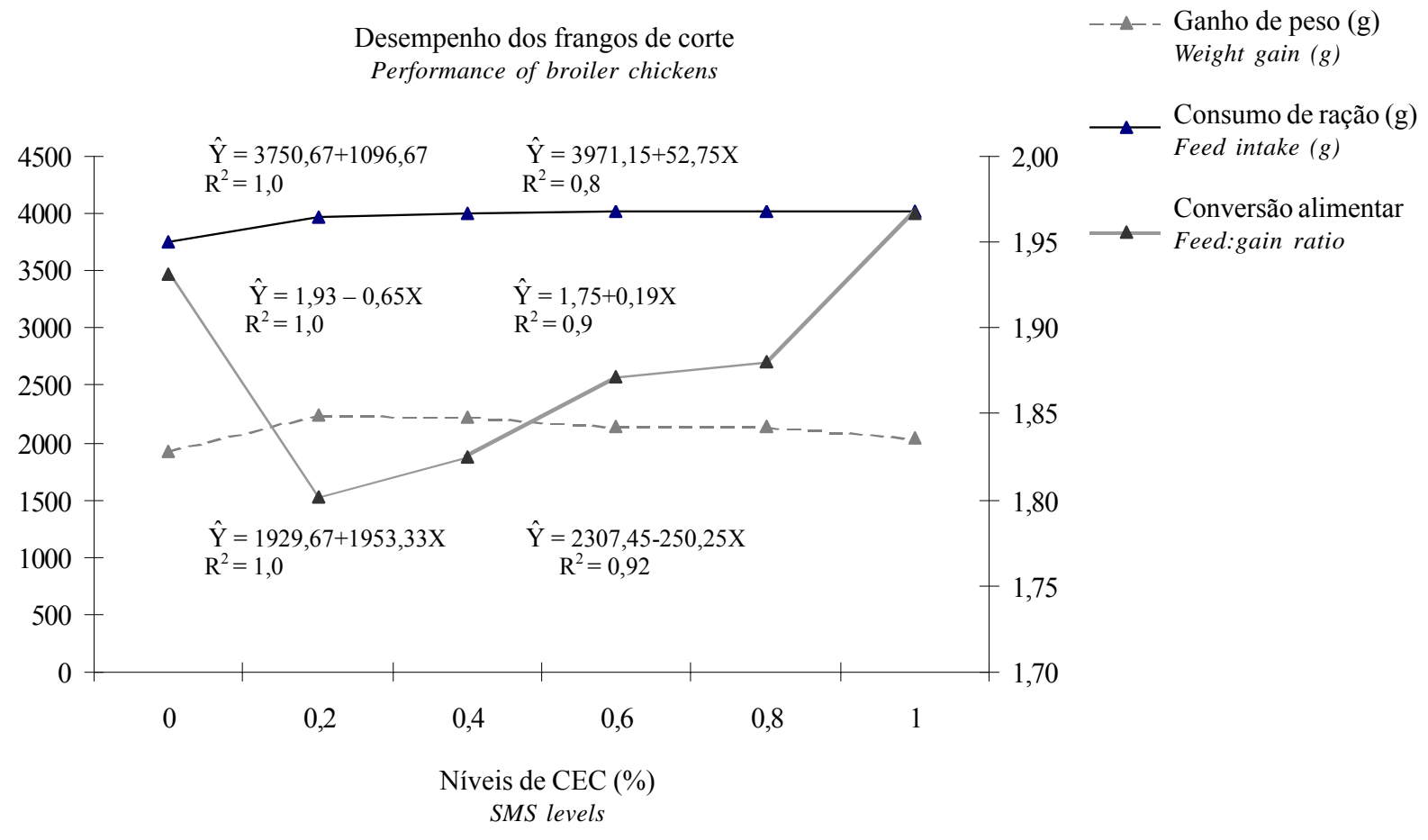

Figura 1 - Desempenho de frangos de corte no período de 1 a 42 dias de idade alimentados com dietas com diferentes níveis do composto exaurido do cogumelo (CEC).

Figure 1 - Performance of broiler chicks from 1 to 42 day old fed diets with different levels spent mushroom substrate (SMS). 
provocado por microrganismos patogênicos no sistema imunológico, deletério ao desempenho das aves.

Os machos apresentaram neste estudo, para todas as características de desempenho avaliadas (Tabela 2), resultados melhores que os obtidos nas fêmeas, o que está de acordo com trabalhos semelhantes realizados anteriormente (Fuini, 2001; Santos et al, 2003, Guo, 2003).

Entre as características de carcaça avaliadas, somente a porcentagem de gordura abdominal foi influenciada pela interação dieta $\times$ sexo, revelando que o efeito das dietas sobre esta característica variou conforme o sexo, pois a porcentagem de gordura abdominal nas aves machos alimentadas com as dietas contendo somente antibiótico foi maior $(\mathrm{P}<0,05)$ que naquelas alimentadas com dietas sem antibiótico e CEC $(0 \%)$ e com 1,0\% de CEC. A porcentagem de gordura abdominal nas aves que receberam antibiótico não diferiu $(\mathrm{P}>0,05)$ da encontrada nas aves alimentadas com as dietas formuladas com 0,2 a $0,8 \%$ de CEC. Conforme se observa nas Tabelas 3 e 4 , entre as demais características de carcaça, somente o rendimento de peito foi afetado $(\mathrm{P}<0,05)$ pela dieta, de modo que os maiores valores foram obtidos com as dietas com antibiótico e com $0,2 \%$ de CEC, que não diferiram entre si. Santos et al. (2003), entretanto, obtiveram maior rendimento de peito ao fornecerem antibiótico e mananoligossacarídeos em comparação ao uso do cogumelo A. blazei desidratado e moído.

Todas as características de carcaça analisadas foram influenciadas $(\mathrm{P}<0,05)$ pelo sexo da ave, portanto, os machos apresentaram rendimentos superiores aos encontrados nas fêmeas.

Em comparação às fêmeas, os rendimentos de peito e de gordura abdominal dos machos foram os únicos parâmetros significativamente influenciados $(\mathrm{P}<0,05)$ pela suplementação com CEC (Tabela 3).

Houve interação dieta $\times$ sexo $(\mathrm{P}<0,05)$ sobre o rendimento de gordura abdominal; as fêmeas acumularam 27,7\% mais gordura que os machos, o que, segundo Bertechini (1998), pode ser atribuído às diferenças fisiológicas entre os sexos, que determinam maior capacidade dos machos de conversão de proteínas em massa muscular, enquanto as fêmeas necessitam de reserva energética maior para suprir as exigências fisiológicas decorrentes da reprodução. Por outro lado, com exceção da dieta com $1 \%$ de CEC, os machos que receberam aditivos nas dietas tiveram maior acúmulo de gordura abdominal, evidenciando melhor aproveitamento nutricional, provavelmente por sofrerem menor ação de microrganismos patogênicos em relação às aves que não receberam aditivos. Santos et al. (2003), no entanto, não observaram efeito da interação dietas $\times$ sexo.
Tabela 3 - Rendimento de carcaça ${ }^{1}$ e dos cortes de frangos no período de 1 a 42 dias de idade alimentados com dietas contendo antibiótico ou diferentes níveis do composto exaurido do cogumelo (CEC)

Table 3 - Carcass yield ${ }^{1}$ and broiler chicks cuts from 1 to 42 day old fed diets with antibiotic or different levels of spent mushroom substrate(SMS)

\begin{tabular}{|c|c|c|c|c|}
\hline \multirow[t]{2}{*}{$\begin{array}{l}\text { Nível de } \\
\text { CEC }(\%) \\
\text { SMS level }\end{array}$} & \multirow[t]{2}{*}{$\begin{array}{c}\text { Rendimento } \\
\text { de carcaça }(\%) \\
\text { Carcass yield }(\%)\end{array}$} & \multirow[t]{2}{*}{$\begin{array}{l}\text { Rendimento de } \\
\text { peito (\%) } \\
\text { Breast yield (\%) }\end{array}$} & \multicolumn{2}{|c|}{$\begin{array}{c}\text { Gordura } \\
\text { abdominal (\%) } \\
\text { Abdominal } \\
\text { fat (\%) }\end{array}$} \\
\hline & & & $\begin{array}{c}\text { Macho } \\
\text { Male }\end{array}$ & $\begin{array}{l}\text { Fêmea } \\
\text { Female }\end{array}$ \\
\hline 0,0 & 74,09 & $27,55^{*}$ & $1,52 *$ & 2,55 \\
\hline 0,2 & 75,05 & 33,82 & 1,88 & 2,29 \\
\hline 0,4 & 73,88 & $28,17 *$ & 1,89 & 2,40 \\
\hline 0,6 & 73,70 & $30,26 *$ & 1,80 & 2,59 \\
\hline 0,8 & 74,68 & $28,93 *$ & 1,89 & 2,21 \\
\hline 1,0 & 73,67 & $28,85^{*}$ & $1,36^{*}$ & 2,38 \\
\hline $\begin{array}{l}\text { Antibiótico } \\
\text { Antibiotic } \\
\text { Macho }\end{array}$ & 76,62 & 34,37 & 1,75 & 2,23 \\
\hline Male & $77,62 \mathrm{a}$ & $32,57 \mathrm{a}$ & 1,72 & - \\
\hline $\begin{array}{l}\text { Fêmea } \\
\text { Female }\end{array}$ & $71,43 b$ & $27,98 \mathrm{~b}$ & - & 2,38 \\
\hline $\begin{array}{l}\text { Média geral } \\
\text { Overall mean }\end{array}$ & 74,53 & 30,28 & 2,05 & \\
\hline CV (\%) & 4,52 & 11,82 & 11,04 & \\
\hline
\end{tabular}

*Diferem do tratamento controle (antibiótico) pelo teste Dunnet $(P<0,05)$ Médias com letras minúsculas distintas na mesma coluna diferem $(P<0,05)$ pelo teste $F$.

${ }^{1}$ Carcaça eviscerada com cabeça, pescoço e pés.

* Differs $(P<0.05)$ from the control treatment (antibiotic) by Dunnet test.

Means, within a column, with different small letters differ $(P<0.05)$ by test $F$.

1 The carcass without viscera, but with head, neck and feet.

Tabela 4 - Rendimento dos cortes de frangos no período de 1 a 42 dias de idade alimentados com dietas contendo antibiótico ou com diferentes níveis do composto exaurido do cogumelo (CEC)

Table 4 - Broiler chicks cuts yield from1 to 42 day old fed diets with antibiotic or different levels of spent mushroom substrate (SMS)

\begin{tabular}{|c|c|c|c|}
\hline $\begin{array}{l}\text { Nível de } \\
\text { CEC (\%) } \\
\text { SMS level }\end{array}$ & $\begin{array}{c}\text { Rendimento } \\
\text { de coxa }(\%) \\
\text { Thigh } \\
\text { yield (\%) }\end{array}$ & $\begin{array}{c}\text { Rendimento de } \\
\text { sobrecoxa (\%) } \\
\text { Over thigh } \\
\text { yield (\%) }\end{array}$ & $\begin{array}{c}\text { Rendimento } \\
\text { de asa }(\%) \\
\text { Wing yield (\%) }\end{array}$ \\
\hline 0,0 & 12,78 & 13,56 & 12,30 \\
\hline 0,2 & 13,74 & 14,87 & 12,21 \\
\hline 0,4 & 12,84 & 14,32 & 11,11 \\
\hline 0,6 & 12,45 & 12,86 & 11,72 \\
\hline 0,8 & 12,93 & 14,15 & 11,58 \\
\hline 1,0 & 13,22 & 14,17 & 11,31 \\
\hline Antibiótico & 13,62 & 13,54 & 11,03 \\
\hline $\begin{array}{l}\text { Antibiotic } \\
\text { Macho } \\
\text { Male }\end{array}$ & $13,68 \mathrm{a}$ & $15,14 \mathrm{a}$ & $12,49 \mathrm{a}$ \\
\hline $\begin{array}{l}\text { Fêmea } \\
\text { Female }\end{array}$ & $12,48 b$ & $12,71 b$ & $10,73 b$ \\
\hline $\begin{array}{l}\text { Média geral } \\
\text { Overall mean }\end{array}$ & 13,08 & 13,92 & 11,61 \\
\hline CV (\%) & 6,79 & 11,94 & 11,86 \\
\hline
\end{tabular}

Médias com letras minúsculas distintas na mesma coluna diferem $(P<0,05)$ pelo teste $\mathrm{F}$.

Means, within a column, with different small letters differ $(P<0.05)$ by test $F$ 


\section{Conclusões}

Considerando os resultados obtidos e as condições em que este trabalho foi realizado, a utilização de $0,2 \%$ de CEC de A. blazei na dieta de frangos de corte pode constituir alternativa ao uso de antibiótico, pois não prejudicou o desempenho produtivo e as características de carcaça das aves.

\section{Agradecimento}

À direção da Escola Agrotécnica Federal de Inconfidentes - MG, por ceder as instalações do Setor de Avicultura para a realização do experimento.

\section{Literatura Citada}

BERTECHINI, A.G. Fisiologia da digestão de suínos e aves. Lavras: FAEPE-UFLA, 1998. 141p.

DABA, A.S.; EZERONYE, U.O. Anti-cancer effect of polysaccharides isolated from higher basidiomycetes mushrooms. African Journal of Biotechnology, v.2, n.12, p.672-678, 2003.

DIAS, E.S.; LABORY, C.R.G.; SILVA, R. Cultivo de cogumelos comestíveis. Lavras: FAEPE-UFLA, 2002. 50p.

EDQVIST, L.R.; PEDERSEN, K.B. Antimicrobials as growth promoters: resistance to common sense. In: EUROPEAN ENVIRONMENT AGENCY: Late lessons from early warnings: the precautionary principle 1896-2000. Copenhagen, OPOCE, 2002. Disponível em: <http:// reports.eea.eu.int/environmental issue report 2001 22/en/ issue-22-part-9.pdf>. Acesso em: 17/12/03.

FUINI, M.G. Utilização do cogumelo Agaricus blazei como alternativa ao uso de antibióticos em rações para frangos de corte. Lavras: Universidade Federal de Lavras, 2001. 64p. Dissertação (Mestrado em Zootecnia) - Universidade Federal de Lavras, 2001.

FUJIMIYA, Y.; SUZUKI, Y.; KATAKURA, R. et al. Tumor-specific cytocidal and immunopotentiating effects of relatively low molecular weight products derived from the basidiomycete, Agaricus blazei Murill. Anticancer Research, v.19, n.1A, p.113-118, 1999.

FUJIMIYA, Y.; SUZUKI, Y.; OSHIMAN, K. et al. Selective tumoricidal effect of soluble proteoglucan extracted from the basidiomycete, Agaricus blazei Murill, mediated via natural killer cell activation and apoptosis. Cancer Immunology Immunotherapy, v.46, n.3, p.147-159, 1998.

GUO, F.C. Mushroom and herb polysaccharides as alternative for antimicrobial growth promoters in poultry. Wageningen: Wageningen University, 2003. 281p. Dissertation (Ph. D. in Animal Sciences) - Wageningen Institute of Animal Sciences, Department of Animal Nutrition, Wageningen University, 2003. Disponível em: <http://www.agralin.nl/wda $>$. Acesso em: 23/12/03.

HUYGHEBAERT, G. Replacement of antibiotics in poultry. In: EASTERN NUTRITION CONFERENCE, 1., 2003, Quebec. Proceedings... Herleen: DSM, 2003. Disponível em: $<\mathrm{http}: / /$ www.dsmnutrafacts.com/enc_03/enc_03_6.pdf>. Acesso em: $17 / 12 / 03$
ITO H.; SHIMURA K.; ITOH H. et al. Antitumor effects of a new polysaccharide-protein complex (ATOM) prepared from Agaricus blazei (Iwade strain 101) "Himematsutake" and its mechanisms in tumor-bearing mice. Anticancer Research, v.17, n.1(A), p.277-284, 1997.

KUMAR, M.T.; HIROOMI, I.; RIKA, N. et al. Immunological effects of extracts of Agaricus blazei grown in submerged culture. In: INTERNATIONAL CONFERENCE OF MUSHROOM BIOLOGY AND MUSHROOM PRODUCTS, 3., 1999, Sydney. Medicinal and value-added mushrooms. Sydney: WSMBMP, 1999. Disponível em: <http://www.worldmushroomsociety.com/upload f2003610144750 3rdICMBMP 016.pdf>. Acesso em: 25/12/03.

MIZUNO, M.; MINATO, K.; ITO, H. et al. Anti-tumor polysaccharide from the mycelium of liquid-cultured Agaricus blazei Murrill. Biochemistry and Molecular Biology International, v.47, n.4, p.704-714, 1999.

MIZUNO, T. Medicinal properties and clinical effects of culinarymedicinal mushroom Agaricus blazei Murril (Agarikomicetideae) (Review). International Journal of Medicinal Mushroom, v.4, n.4, p.298-311, 2002.

MIZUNO, M.; MORIMOTO, M.; MINATO, K. et al. Polysaccharides from Agaricus blazei stimulate lymphocyte $\mathrm{T}$-cell subsets in mice. Bioscience, Biotechnology and Biochemistry, v.62, n.2, p.434-437, 1998.

MONTAGNE, L.; PLUSKE, J.R.; HAMPSON, D.J. A review of interactions between fibre and the intestinal mucosa, and their consequences on digestive health in young nonruminant animals. Animal Feed Science and Technology, v.108, p.95-117, 2003.

PALERMO-NETO, J. A questão dos resíduos de antimicrobianos em avicultura: verdade ou protecionismo europeu? Revista Conselho Federal de Medicina Veterinária, v.9, n.28-29, p.25-32, 2003.

RESHETNIKOV, S.P.; WASSER, S.P.; TAN, K.K. Higher basidiomycota as a source of antitumor and immunostimulating polyssaccharides (Review). International Journal of Medicinal Mushrooms, v.3, p.361-394, 2001.

RINKER, D.L. Handling and using "spent" mushroom substrate around the world. In: INTERNATIONAL CONFERENCE OF MUSHROOM BIOLOGY AND MUSHROOM PRODUCTS, 4. 2002, Cuernavaca. World wide production of mushrooms. Cuernavaca: WSMBMP, 2002. Disponível em: <http:// www.worldmushroomsociety.com/upload/ f2003610144734 4thICMBMP_005.pdf $>$. Acesso em: 25/12/03.

ROSTAGNO, H.S.; ALBINO, L.F.T.; DONZELE, J.L. et al. Tabelas brasileiras para aves e suínos: composição de alimentos e exigências nutricionais. Viçosa, MG: Editora UFV, 2000. 141p.

SANTOS, E.C.; TEIXEIRA, A.S.; BORGES, P.R. et al. Uso de beneficiadores de crescimento sobre o desempenho, características de carcaça e bactérias totais do intestino de frangos de corte. In: REUNIÃO DA SOCIEDADE BRASILEIRA DE ZOOTECNIA, 40., 2003, Santa Maria. Anais... Santa Maria: Sociedade Brasileira de Zootecnia, 2003. (CD-ROM).

SILVA, L.P.; NÖRNBERG, J.L. Prebióticos na nutrição de não ruminantes. Ciência Rural, v.33, n.5, p.983-990, 2003.

UNIVERSIDADE FEDERAL DE VIÇOSA - UFV. SAEG - Sistemas para análises estatísticas e genéticas. Versão 7.1. Viçosa, MG: 1997. 150p. (Manual do usuário).

WONG, C.K.; LEUNG, K.N.; FUNG, K.P. et al. Immunomodulatory and anti-tumor polysaccharides from medicinal plants. Journal of International Medicinal Research, v.22, n.6, p.299-312, 1994

Recebido: 25/05/05 Aprovado: 09/02/07 